\title{
Factors Influencing Walking Distance to the Preferred Public Transport Stop in selected urban centres of Czechia
}

\author{
Igor Ivan ${ }^{1 凶}$ - Jiřri Horák ${ }^{1}$ - Lenka Zajíčková ${ }^{2}-$ Jaroslav Burian $^{2}-$ David Fojtík $^{3}$ \\ ${ }^{1}$ Department of Geoinformatics, Faculty of Mining and Geology, VSB-Technical University of Ostrava, 17. listopadu 2172/15, \\ Ostrava, Czechia \\ ${ }^{2}$ Department of Geoinformatics, Palacký University Olomouc, 17. listopadu 50, Olomouc, Czechia \\ ${ }^{3}$ Department of Control Systems and Instrumentation, Faculty of Mechanical Engineering, VSB-Technical University of Ostrava, 17. \\ listopadu 2172/15, Ostrava, Czechia \\ 凶igor.ivan@vsb.cz
}

\begin{abstract}
One of the ways of improving the attractiveness of public transport is to bring it closer to its potential users. A long walking distance from a stop is often one of the critical factors limiting its more frequent and extensive use. Studies dealing with the accessibility of transport networks usually work only with the closest stop. This article analyses the actual walking distance from the place of residence to the preferred stop. The survey used a questionnaire method and was conducted in two cities in the Czech Republic-Ostrava and Olomouc. Based on the results of the study, the average walking distance was assessed and the impact of demographic characteristics (gender, age, education, number of members in the household, economic activity, the presence of a child in the household, and car ownership), transport behavior (preferred mode of transportation, car convenience and opinions on public transport), and urban characteristics (prevailing housing type) on the walking distance were analyzed. The main findings prove a significant impact on walking distance by a number of these factors, but the preferred use of a car for commuting or unemployment does not significantly affect walking distance.
\end{abstract}

\section{Keywords}

Walking distance, public transport, questionnaire, public transport stop, Ostrava,

Olomouc

Received: 18 January 2018

Received in revised form: 08 May 2019

Accepted:

11 May 2019

Highlights for public administration, management and planning:

- The public transport stop reported as being closest to a respondent's residence was used by only $51 \%$ of all respondents in the survey. Another $20 \%$ of residents used the second closest stop, $11 \%$ the third stop.

- Travellers select the stop based on number of connections; seamless connection; the speed of connection; potential delays; equipment of stops and nearby areas; the comfort of the vehicle; avoiding overcrowded stop; other personal factors.

- The average walking distance to the preferred stop is 568 metres in Ostrava while only 439 metres in Olomouc.

- Significantly shorter distances refer to the female population in Ostrava, retired and unemployed. Assumption of the negative influence of the higher number of family members, higher salaries, car ownership and worse education (blue collar) was not proved.

\section{Introduction}

Today's cities are crowded with a growing number of transport vehicles, which brings many adverse effects ranging from congestion, increased noise, and $\mathrm{CO}_{2}$ emissions to growing danger for both drivers and pedestrians. With the increasing num- ber of vehicles, there is also a rising demand for improvement of the transport infrastructure, particularly the pressure to build new roads or to increase the capacity of existing ones, as well as the related pressure to increase the number of parking spaces. Many cities cater to their citizens' demands; however, this newly created capacity will soon be filled again. The situation in the Czech Republic is no 
exception, and development there follows trends in Western European countries (Seidenglanz 2007). Čekal (2006) notes that whereas in 1970, fewer than $5 \%$ of commuters used a car to commute to work outside their hometown, by 2001 that number had grown to more than $30 \%$. According to data from the last census, in 2011, cars (incl. drivers and passengers) were used in any step of travel chain by more than $44 \%$ of commuters, meaning that individual transport has become, over the past few years, the dominant mode of transport. This development is confirmed by the number of cars per capita; in 1950, there were only 15 cars per 1,000 residents; by 1990, there were 233 per 1,000 residents (Kraft 2011); and by the beginning of 2019, there were 598 cars per 1,000 residents $(15+$ years old). For more detail on the transformation period and the increase in individual transport in the Czech Republic, see Pucher 1999.

The growing popularity of individual transport is reflected in a decrease in the volume of passengers serviced by public transport. Between 1995 and 2014, railway use recorded a decline of more than $22 \%$ and bus transport use decreased by almost $50 \%$. There was also an overall $5.5 \%$ decrease in passengers using passenger transport (individual and public) between 1995-2014 (MD 2014). However, the same source claims a 9\% increase in passenger-kilometres. This implies that people commute less frequently, but they do so for longer distances. In recent years, there has been an evident change in the use of rail-after years of decline, there was an increasing trend, by $4 \%$, in the number of passengers since 2011.

Two cities located in the eastern part of the Czech Republic were chosen for the analysis. Both of them are regional capitals, and Ostrava has nearly 300,000 inhabitants, and Olomouc has slightly more than 100,000 inhabitants. Both cities are different regarding their urban structure. Olomouc is a typical historical city whose development was affected for a long time by the existence of city walls. In contrast, Ostrava is a relatively young industrial city founded through the gradual annexing of the surrounding villages, which were subsequently heavily urbanised, the results of which often were undeveloped gap sites between them. Thus, Ostrava represents a typical polycentric city (Hruška-Tvrdý et al. 2012; Burian et al. 2015). In both cities, public transport provides transport services as part of an integrated transport system that covers nearly the whole region (Olivková 2015; Zajíčková 2012). Urban public transport in studied cities creates a part of the integrated transport system and is operated by local public transit agencies servicing the area of the city and several surrounding municipalities. Table 1 summarises the basic characteristics of urban public transport in both cities. While Ostrava is almost three times higher in population than Olomouc, the total number of passengers transferred in 2014 is less than two times higher. This difference is caused mainly due to the higher relative number of daily commuters travelling to Olomouc and higher preference of urban transit than in Ostrava. A higher number of vehicle-kilometres and seat-kilometres is caused by differences in areas and the number of routes. Regarding the number of stops, while Olomouc has a denser number of stops per $\mathrm{km}^{2}$, Ostrava has a higher number of stops per population. Nevertheless, both cities are facing quite severe decreases in passengers. During the last five years (2010-2014), the number of transferred passengers dropped about $10 \%$ in Olomouc and even about $14.4 \%$ in Ostrava.

Table 1 Characteristics of urban public transport in Ostrava and Olomouc in 2014

\begin{tabular}{lll}
\hline Characteristic & Ostrava & Olomouc \\
\hline * Population of city & 294,200 & 99,809 \\
Area of city $\left(\mathrm{km}^{2}\right)$ & 214 & 103.4 \\
No. of passengers (thous.) & 91,000 & 52,193 \\
Vehicle km (thous.) & 31,820 & 6,196 \\
Seat kilometres (thous.) & $3,301,825$ & 651,153 \\
Number of routes & 82 & 31 \\
Number of stops & 633 & 178 \\
Route length (km) & $1,025.3$ & 317 \\
No. of routes per 1,000 people & 0.28 & 0.31 \\
No. of stops per 1,000 people & 1.62 & 0.56 \\
No. of stops per km ${ }^{2}$ & 0.34 & 0.58 \\
No. of people per 1 stop & 464.8 & 560.7 \\
\hline
\end{tabular}

Source: Ostrava Transport Agency and Transport Agency of Olomouc; * population 1. 1. 2015

One of the main transport policy strategies of most cities is reducing the number of cars that travel in the city. Car parks with links to urban public transport are being built to reduce the number of cars entering cities (e.g., in Ostrava). The creation of low-emission zones is considered (e.g., in Prague), and parking in city centres in all major cities is limited (or is subject to a fee). However, these provisions do not affect the situation regarding the vehicles of people living in a city, who also frequently use cars for commuting, for example, to work. In this case, the standard policy is increasing the attractiveness of urban public transport. It is necessary to improve the quality of public transport services (a list of quality indicators is provided by L'uptak et al. 2017). A key factor 
affecting the use of public transport is the accessibility of a transport network, i.e., of public transport stops. This article aims to evaluate the declared behaviour of residents of Ostrava and Olomouc regarding their access to public transport stops, to evaluate walking distances and influencing factors. Several factors that may affect resident walking distance were assessed, including socio-demographic and urban factors as well as the declared transport behaviour of respondents.

Ongoing changes of regional and urban public transport organisation in Ostrava are focused on reducing transport emissions in the city centre by building new terminals of regional buses in the suburb with secure transfers to urban transport (mostly electrified - trams and trolleybuses). Thus, the reorganisation is in progress and open to absorb new suggestions in the transport organisation. The findings will be used by local transit agencies to improve the routing and related distribution of transport stops. The results should also contribute to the understanding of the role of public transport stops in accessibility mapping and evaluation, where still usage of the closest stop dominates and creates negative bias in accessibility evaluation of the given locality. Such results will be useful for other public transport planners and researchers to change the current methodology of accessibility evaluation.

\section{Access to public transport stops}

Physical access to public transport stops is considered as one of four basic categories of indicators for assessing the transport accessibility of public transport (Mavoa et al. 2012; Fransen et al. 2015). In addition to the accessibility of transport stops, studies include in their assessments the length (in terms of time, distance or price) of a journey by public transport, the accessibility of destinations by public transport, and the number of connections. As for stop access, physical access in terms of time and distance are specifically measured, although, in the case of walking to a stop, the distance itself is preferred (Loutzenheiser 1997). Moreover, there is a consensus on the preference of the use of real walking distance versus Euclidean distance, which overestimates the results (El-Geneidy et al. 2009; Bilková et al. 2017).

Analyses of stop accessibility can be divided into two categories. The first includes the delimitation of areas around stops or the service areas along public transport routes. Subsequently, the population living in the service areas is defined. Based on the level of detail, this population is defined as a total population of administrative units with centroids inside the service areas or as a share of the population that is proportional to the percentage of the area falling into service area or the percentage of the street network length. A uniform distribution of the population is assumed (e.g. O’Neill et al. 1992; Hsiao et al. 1997; Peng et al. 1997; Ayvalik Khisty 2002). This significant aggregation and simplification, however, has a severe impact on the accuracy of results, whereas the Modifiable Areal Unit Problem (MAUP) persists to be an essential aspect (Fotheringham \& Wong 1991), changing results according to different delimitations of geographical units. Unsatisfactory outcomes of this approach are also confirmed by Currie (2010).

The general procedure to minimise the error resulting from MAUP is the conversion to a more detailed administrative unit (e.g., Zhao et al. 2003; Furth et al. 2007; Gutiérrez \& García-Palomares 2008; Biba et al. 2010). Work at the level of individual parcels or address points is recommended to be the most accurate for evaluating and defining the service area of a transport network (Biba et al. 2010). With the availability of detailed data, analyses evaluating access to public transport at the micro level also appear (García-Palomares \& Gutiérrez 2013).

The second category of analysis involves walking distance to a public transport stop that potential users are willing to cover. In the case of limiting walking distance, there is a consensus in the literature on 400 meters and 800 meters being the maximum walking distance to a bus or train stop (e.g., O'Neill et al. 1992; Hsiao et al. 1997; El-Geneidy et al. 2009; Daniels \& Mulley 2013; Kraft 2016; Burian et al. 2018). However, there are also other distances and dependencies between the use of public transport and walking distance. Loutzenheiser (1997) indicates that with every additional 500 meters to a transport stop, the likelihood of walking decreases by $50 \%$. Similarly, Dill (2003) reports that each $10 \%$ increase in walking distance causes a $10 \%$ decrease in the use of public transport. However, there are calls for a reassessment of the designated distances in both directions (Kimpel et al. 2007; El-Geneidy et al. 2014). The distance and willingness of the residents to walk to the transport stops vary significantly across states and even cities. Langford et al. (2012) and ElGeneidy et al. (2014) provide an extensive overview of walking distances. In the Czech Republic, limits for maximal walking distances to the closest public transport stops should be defined by NUTS3 re- 
gional authorities but often are quantified poorly or not at all. The Institute for Spatial Development (founded by the Ministry of Regional Development of the Czech Republic) recommends locating urban public transport stops within 500 meters from origins and destinations (Hyvnar \& Rohrerová et al. 2016).

El-Geneidy et al. (2014) also present extensive research into the impacts that further affect the willingness of passengers to walk to public transport stops. The main positive factor is the short (minimum) distance and time in which a passenger can reach a stop, followed by individual characteristics, parameters of the stop (its accessories) and the location, characteristics of the particular transport line, and weather. By using examples of scientific papers listed herein, it is possible to reach several conclusions:

- Higher-income households and blue-collar neighbourhoods negatively affect the willingness to walk.

- A higher number of members of a household and higher education positively affect the willingness to walk.

- Car ownership negatively affects the willingness to walk; however, if the drivers already walk, they are willing to walk even longer distances.

- A willingness to walk is increased with increasing access to a transport network.

- A higher number of transport lines stopping at the stop increases the acceptable distance of walking.

- Increasing waiting time and the number of transfers reduce the acceptable distance of walking.

- The effect of temperature or weather is uncertain and varies according to the geographical localisation of the study, presumably depending on the habits of the residents.

In addition to determining the size of the population (or the population structure) in a certain distance from stops and transport network, other indicators to assess the transport accessibility of the transport network are used-for example, PTAL (Wu and Hine 2003), LUPTAI (Yigitcanlar et al. 2008), or a supply index SI (Currie 2010). Although these parameters well describe the accessibility of the network, as stated by Fransen et al. (2015), they do not assess whether it is possible to get from these stops to the desired destinations within a reasonable travel time and at the desired time of arrival. Moreover, lower access to public transport stops can be compensated by higher accessibility of the desired targets in the vicinity of one's home and, therefore, within his/her walking distance.

\section{Data source}

The above results of walking distances are based on logical deductions and may not be representative of actual walking distances. In addition to the factors affecting willingness to walk to a stop, there is the subjective factor, which is based on the personal preference of a specific stop or a route to it that plays a role in the final decision. This possibility of choice represents one of the challenges in the study of transport accessibility (van Wee 2016). To determine the real route walked by the commuters, we can take advantage of the results of surveys. This way of data collection is not innovative and is commonly used (e.g., Daniels \& Mulley 2013; El-Geneidy et al. 2014; Hernández and Witter 2015), although the use of advanced information technology has become more and more up to date using both localization by mobile phones or data from social networks (Witlox 2015).

The findings presented below were derived from a survey carried out between September 22-26, 2014, in Ostrava and Olomouc and surrounding municipalities serviced by urban public transport links. The survey was conducted in collaboration with the Ostrava Transport Agency and the Olomouc City Council. The PAPI method was applied, and the quota sampling of respondents uses stratification according to gender, age and education level. Cities were divided into 13 and 11 zones respectively to assure even territory distribution of respondents. A total of 1,041 respondents took part the questionnaire survey (51\% from Ostrava and $49 \%$ from Olomouc) and the representative sample structure corresponded to the population of both cities regarding gender, age, and education. The questionnaire contained a total of 17 questions and a travel diary, in which the two questions were directly focused on the walking distance to a stop:

- How long does it take you to walk from your home to the urban public transport stop that you use most often (in minutes)? What is the name of this stop? 


\section{Sciendo}

- How long does it take you to reach (by walk/vehicle) the bus stop or railway station that you use most often (in minutes) from your home? What is the name of this stop?

Respondents were asked to provide their residence address, but this item was not always completed. The process of geocoding was preceded by data harmonisation, which consisted of modifications of the recorded names of cities and streets according to their official names. Of the total number of questionnaires, 187 records contained complete addresses (18\%), 798 records provided only the name of the street (77\%), and 56 records provided only the name of the city district or the city $(5 \%)$. To reduce errors in the evaluation of walking distance to a stop, the questionnaires that were not geocoded at least on the street level were removed; a total of 985 questionnaires remained and were used. In this case, a centroid of the street was used. Respondents also were asked to name the public transport stop and bus/train stop that they use most often. The harmonisation consisted of the correction of the names, but, in the case of both types of transport (urban and suburban), in some cases, a problem arose with stops. Especially in more remote areas of surrounding municipalities, which are not completely serviced by urban public transport, respondents considered either a stop with only suburban transport to be an urban transport stop or a stop serviced by urban public transport however, that was many kilometres away from their place of residence, meaning that walking to this stop was unrealistic. Similarly, in the case of suburban transport stops, the respondents reported the stops where only urban public transport stopped.

The records were corrected and, if not possible, were removed to process all the information. The records with no specified stop also were removed. For harmonisation and geocoding purposes, the list of stops from the timetables provided by CHAPS, Inc., (administrator of the Central information system containing timetables of all transport operators in the Czech Republic) was used. In total, 936 questionnaires (47\% from Ostrava and 53\% from Olomouc) were entered into the evaluation.

It is important to note that the respondents to the questionnaire were not only public transport commuters but also residents with no ties to the mode of transport used. The responses show that approximately $50 \%$ of all respondents in both cities most often used public transport for their commute; $25.3 \%$ of respondents used a car in Ostrava, as opposed to $21.1 \%$ in Olomouc (Table 2). Others rode a bicycle, walked on foot, or freely combined transport modes (i.e. park-and-ride).

Table 2 Transport mode use of respondents in Ostrava and Olomouc

\begin{tabular}{lrr}
\hline Transport mode & Ostrava & Olomouc \\
Car/motorbike & $25.3 \%$ & $21.1 \%$ \\
Walk/bicycle & $13.5 \%$ & $26.6 \%$ \\
Public transport & $54.4 \%$ & $48.7 \%$ \\
Combination/other/unknown & $6.8 \%$ & $3.7 \%$ \\
Total number of respondents & 443 & 493 \\
\hline
\end{tabular}

Source: authors

\section{Walking distance and time}

As stated, a walking distance is preferred when trying to assess access to individual stops, but the questionnaire focused on assessing the time needed to get to a public transport stop that was used most frequently for a commute by the respondent. The average walking time in both cities was 6 minutes. The evaluation of walking time for individual cities shows that in Olomouc, 83\% of respondents had a public transport stop within a 5-minute walk from their home (37.5\% reported precisely 5 minutes), and in Ostrava, it was only $55.2 \%$ of the respondents (similarly, $31.3 \%$ reported precisely 5 minutes). In total, $99.5 \%$ of respondents in Olomouc were able to reach the stop within 10 minutes; in Ostrava, it was $86.5 \%$. On average, the respondents in Ostrava walked 7.5 minutes to their public transport stop, and the respondents in Olomouc took 3 minutes less. The difference between walking distances in both cities was confirmed by an ANOVA test ( $\alpha=95 \%$ ). However, the variability of Ostrava entries was higher (more than twice the standard deviation). The walking time median amounted to 5 minutes in both cities. This value is influenced by some rounding off in the responses, from which it is evident that interviewers were able to distinguish, for a 5-minute walking time limit, the length of a walking minute by minute, whereas longer walking times often were reported only as multiples of 5 .

For further analyses of walking distance, specific metric distances of a walk to a public transport stop were calculated. The Network Analyst in the ArcGIS (Esri) program was used with the street network StreetNet by CEDA, Inc. These data are more accurate and comprehensive (regularly updated, clearly defined way of data collection, guaranteed accuracy, defined measure) than, for example, the freely 

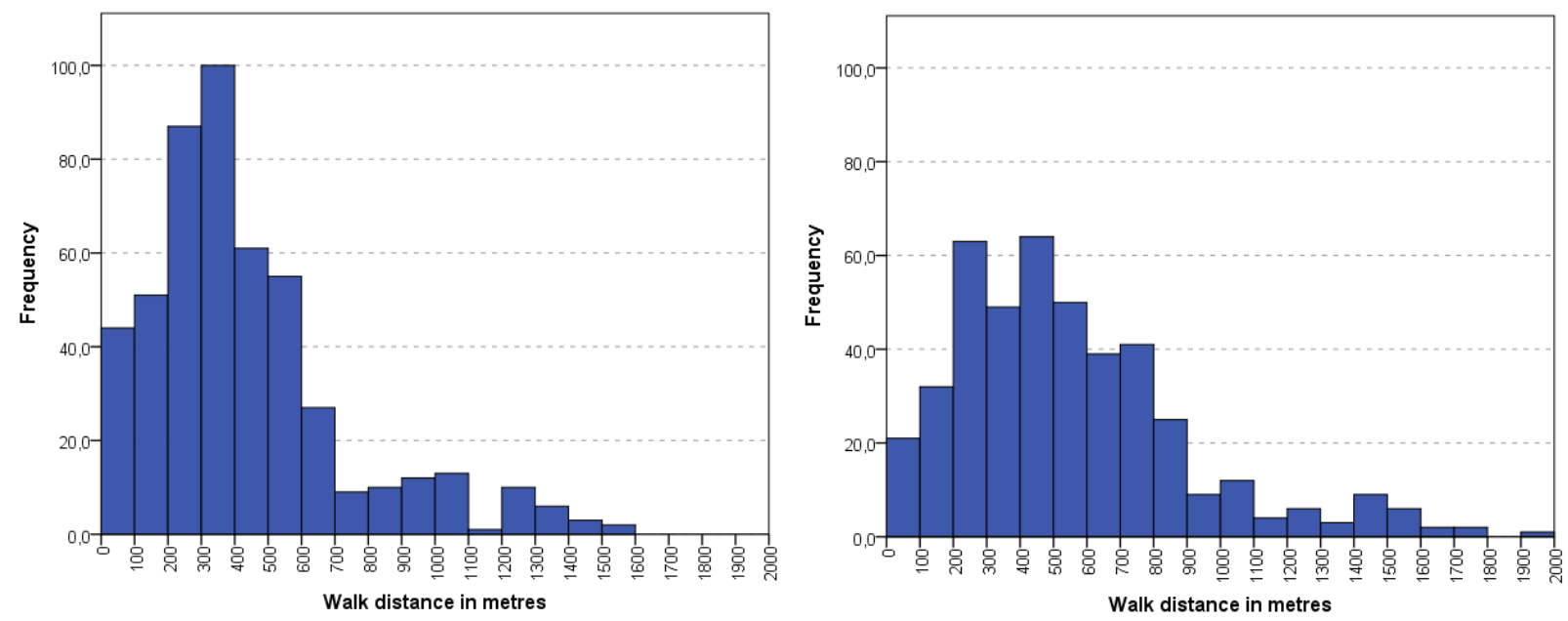

Fig. 1 Walking distance to preferred stop in Olomouc (left) and Ostrava (right), authors.

available data from OpenStreetMap (i.e. Durček \& Horňák 2016). Still, a certain degree of approximation overestimates results, since an individual can use a denser network of sidewalks and shortcuts (e.g., across the lawn, park, or open space) (Kozel, Orlíková, Michalcová, 2018). However, the results may also be underestimated, because instead of the shortest route, an individual can use a longer but more attractive route that is preferred for safety or other reasons. Another influence on results can also be caused by a high proportion of localised residences on street centroids (77\%). However, the results provide a valid view of walking distances in an urban environment.

Regarding the resulting distances, only seven records were longer than $2 \mathrm{~km}$ (the maximum 2.5 $\mathrm{km})$. In the case of the minimum distances, fewer than $7 \%$ of respondents stated that their walking distance was up to 100 meters. However, in terms of time, the respondents reported a period of 0.5-10 minutes (median 3 minutes).

Frequency distributions of walking distances for both cities are separately shown in Fig. 1. Differences are apparent from both histograms. Both distributions are heavily left-skewed (coefficient of skewness of 1.5, 1.9), yet there is a significant difference in the kurtosis of data when the walking distances in Olomouc (5.6) are much more concentrated than in Ostrava (3.1). This fact is due to the different urban structures of the cities, as explained earlier. The average distance to a stop used in Ostrava is approximately 130 meters longer than in Olomouc and reaches 568 meters. However, half of all routes are shorter than 488 meters (or 356 m), $25 \%$ of the routes are within 290 meters (237 $\mathrm{m})$, and $75 \%$ are within 738 meters $(543 \mathrm{~m})$. Di- vergence in walking distances in both cities also was confirmed by a statistically significant t-test (two-tailed) at the significance level of 95\%.

\section{Influence of external factors on walking distance}

Various demographic factors of respondents, their declared transport behaviour, or urban characteristics of the place where they live may affect the distance of the walk. For the evaluation, 11 indicators were selected and were included in the questionnaire or could be derived from the answers (see Table 3). The evaluation was carried out in two steps-evaluation of the influence of selected factors on the walking distance to a stop in both cities simultaneously and evaluation of the situations in both cities separately. In addition to the centrality of distribution (mean, LQ: $25 \%$ quartile, median, UQ: $75 \%$ quartile) and data variability (SD: standard deviation), the statistical difference of walking distances between the groups was also assessed. One group was selected as a benchmark, and other groups were compared to it using the two-tailed ttest.

The results in Table 4 show that although there are often significant differences between the average distances, depending on demographic characteristics, only a few are statically significant compared to the benchmark. It is possible to confirm that the walk of respondents ages 15-24 is significantly longer than the walk of respondents ages 45-64. It is necessary to emphasise the high SD value in this youngest age group because they 
Table 3 Potential explanatory variables

\begin{tabular}{ll}
\hline Type of Variable & \\
\hline & Gender: male, female \\
& Age: 15-24, 25-34, 35-44, 45-64, 65+ \\
& Education: primary school and lower, secondary school (without GCSE), \\
Demographic & secondary school (with GCSE), university \\
characteristics & Number of household members: 1, 2, 3, 4, 5+ \\
& Economic activity: student, employee, entrepreneur, unemployed, pensioner, maternity/parental leave \\
& Child in household: yes, no \\
& Car in household: yes, no \\
\hline Transport & Preferred means of transport: car, urban public transport, bus, train, walk, bike, motorcycle \\
behaviour & Convenience of the car: a longer commuting time while using \\
& public transport: <0, 0-9, 10-19, 20-29, 30-59, 60+. \\
& Opinions on public transport: is it attractive or not, reliable, safe, clean, comfortable, fast and cheap \\
\hline Urban & Housing type: urban housing incl. estates, family houses, suburbs \\
characteristics & \\
\hline
\end{tabular}

Source: authors

show several of the longest walks (see the previous section). Also, the second youngest group, ages 25-34 years, who also walk a longer distance, is on the edge of statistical significance. The trend confirms that with increasing age, a declared walking distance to public transport stop is declining, which has been confirmed for at least the youngest respondents. Also, gender proved to be a significant factor influencing walking distance; significantly men walk longer distances than women. Regarding walking time, however, both groups declared 5.5 minutes, meaning that men get to the stop faster than women. This difference is caused by their longer strides, as confirmed in other studies as well (e.g., Bernard 2012; Whyte 2012).

Economic activity shows the most important influence of all demographic characteristics. A group of entrepreneurs was used as a benchmark. Pensioners walk significantly shorter distances because they probably prefer to live closer to the public transport network or prefer closer stops (not preferred by younger travellers) over better serviced remote stops or they resign from using public transport if stops are distant. Surprisingly, another group with short distances were the unemployed, who, although they live close to public transport stops and accessibility to their residence is good, are unable to find a job. Since an employee lives a similar distance from a transport stop as an unemployed person, the accessibility of transportation services plays a marginal role in the issue of unemployment. Other variables did not show any statistically significant influence on walk distance. Education did not have any significant influence on walk distance, although there was a slight increase in walking distances with increasing education. Similarly, with an increasing number of household members, there was a slight increase in the walk to a stop. Individuals were willing to walk a similar distance regardless of whether they raise a child or not. The ownership of a car, which nowadays is almost standard, had no impact either.

Of the listed transport characteristics, the most frequently-used mode, surprisingly, did not influence the distance of the walk. From the results (Table 5), it is evident that respondents using public transport live slightly closer to a stop than respondents using other modes of transport (including walking), who declare a similar walk distance.

The questionnaire also included seven questions to evaluate respondent opinions on the quality of public transport. A four-point scale was used for the evaluation, where the first and last two variants (yes + rather yes, or no + rather not) were merged for testing. As it turned out, respondents who positively evaluated public transport walked a shorter distance to a stop, and it can be assumed that they also increasingly use it and tend to evaluate public transport as a fast (eliminating long and slow walk), attractive (it is closed) and reliable (more flexible accessible). Conversely, people who were mostly negative in their evaluations showed a longer walking distance to public transportation. This fact is reflected in the assessment of the attractiveness, reliability, comfort, speed, and price of public transport. Only two factors had no significant impact-cleanliness and safety of public transport. 
Table 4 Influence of demographic characteristics on walking distance (in meters)

\begin{tabular}{|c|c|c|c|c|c|c|c|c|}
\hline Variable & Category & $\mathrm{N}$ & Mean & $\mathrm{p}$-value & SD & LQ & Median & UQ \\
\hline \multirow{5}{*}{ Age } & $15-24$ & 160 & 703.6 & 0.006 & 829.3 & 275.5 & 473.4 & 735.0 \\
\hline & $25-34$ & 176 & 595.0 & 0.057 & 485.4 & 288.1 & 485.5 & 766.2 \\
\hline & $35-44$ & 200 & 529.5 & 0.320 & 489.2 & 266.1 & 394.9 & 640.6 \\
\hline & $45-64$ & 251 & 507.7 & base & 440.5 & 274.3 & 413.8 & 613.6 \\
\hline & $65+$ & 167 & 462.9 & 0.382 & 338.2 & 233.4 & 376.5 & 647.6 \\
\hline \multirow{2}{*}{ Sex } & Male & 451 & 587.0 & base & 616.0 & 263.4 & 431.6 & 671.3 \\
\hline & Female & 503 & 523.2 & 0.005 & 446.0 & 274.3 & 421.2 & 661.5 \\
\hline \multirow{6}{*}{ Economic status } & Retired & 191 & 459.6 & 0.001 & 353.5 & 236.6 & 374.0 & 588.9 \\
\hline & Parental leave & 53 & 596.3 & 0.856 & 578.6 & 246.7 & 413.4 & 784.0 \\
\hline & Unemployed & 48 & 525.8 & 0.026 & 323.8 & 276.5 & 521.7 & 640.0 \\
\hline & Entrepreneur & 63 & 640.1 & base & 654.1 & 293.6 & 438.2 & 754.6 \\
\hline & Student & 163 & 629.9 & 0.874 & 705.3 & 265.1 & 447.6 & 718.4 \\
\hline & Employee & 434 & 552.7 & 0.106 & 515.2 & 276.2 & 434.1 & 658.8 \\
\hline \multirow{4}{*}{ Education } & Primary school & 79 & 527.2 & 0.789 & 274.3 & 653.5 & 415.3 & 565.9 \\
\hline & Secondary school without GCSE & 236 & 519.3 & 0.860 & 263.4 & 599.5 & 398.8 & 489.7 \\
\hline & Secondary school with GCSE & 388 & 564.7 & 0.122 & 244.8 & 677.0 & 421.6 & 576.3 \\
\hline & University & 250 & 575.2 & base & 313.3 & 692.9 & 470.1 & 495.7 \\
\hline \multirow{5}{*}{ People in household } & 1 & 98 & 510.8 & 0.390 & 409.5 & 235.8 & 445.3 & 649.1 \\
\hline & 2 & 306 & 525.6 & base & 477.2 & 267.6 & 392.7 & 650.0 \\
\hline & 3 & 240 & 534.5 & 0.834 & 573.1 & 274.7 & 408.7 & 617.1 \\
\hline & 4 & 196 & 615.1 & 0.055 & 647.3 & 249.2 & 456.9 & 733.2 \\
\hline & 5 and more & 114 & 598.2 & 0.913 & 462.9 & 312.7 & 487.3 & 754.5 \\
\hline \multirow{2}{*}{ Child in household } & No & 676 & 539.9 & base & 513.9 & 263.5 & 413.8 & 666.5 \\
\hline & Yes & 278 & 586.1 & 0.218 & 579.2 & 276.1 & 442.7 & 662.8 \\
\hline \multirow{2}{*}{ Car in household } & No & 259 & 532.1 & base & 466.7 & 274.3 & 401.8 & 655.6 \\
\hline & Yes & 685 & 563.8 & 0.145 & 560.4 & 261.4 & 438.2 & 678.5 \\
\hline
\end{tabular}

Source: authors

Table 5 Influence of transport characteristics on walking distance (in meters)

\begin{tabular}{llrrrrrrl}
\hline Variable & Category & N & Mean & p-value & SD & LQ & Median & UQ \\
\hline \multirow{4}{*}{ Preferred transport mode } & Car/motorbike & 221 & 592.5 & 0.484 & 523.6 & 292.8 & 454.6 & 685.1 \\
& Walk/bicycle & 196 & 590.8 & 0.070 & 604.9 & 248.1 & 431.7 & 693.1 \\
& Public transport & 489 & 528.3 & base & 516.4 & 263.0 & 411.3 & 647.0 \\
& Other & 48 & 476.5 & 0.950 & 428.1 & 194.9 & 337.4 & 688.8 \\
\hline \multirow{2}{*}{ Attractive PT } & No & 402 & 635.9 & base & 669.4 & 285.6 & 457.0 & 738.8 \\
& Yes & 548 & 495.4 & $\mathbf{0 . 0 0 1}$ & 398.2 & 256.0 & 399.1 & 624.5 \\
\hline \multirow{2}{*}{ Reliable PT } & No & 133 & 714.3 & base & 836.0 & 275.5 & 475.6 & 704.6 \\
& Yes & 819 & 528.4 & $\mathbf{0 . 0 0 1}$ & 462.6 & 266.8 & 417.6 & 658.6 \\
\hline \multirow{2}{*}{ Clean PT } & No & 353 & 600.8 & base & 575.6 & 289.8 & 450.9 & 689.5 \\
& Yes & 597 & 526.7 & 0.246 & 507.2 & 256.0 & 401.8 & 641.4 \\
\hline \multirow{2}{*}{ Safe PT } & No & 211 & 538.3 & base & 504.0 & 248.1 & 413.8 & 648.8 \\
& Yes & 741 & 558.9 & 0.647 & 542.5 & 274.3 & 429.3 & 671.0 \\
\hline \multirow{2}{*}{ Comfortable PT } & No & 373 & 632.2 & base & 677.1 & 288.6 & 462.8 & 695.9 \\
& Yes & 578 & 504.2 & $\mathbf{0 . 0 0 1}$ & 410.0 & 259.4 & 394.6 & 647.3 \\
\hline \multirow{2}{*}{ Fast PT } & No & 307 & 637.2 & base & 665.0 & 290.9 & 455.2 & 724.6 \\
& Yes & 645 & 514.9 & $\mathbf{0 . 0 0 1}$ & 454.1 & 257.2 & 410.1 & 655.2 \\
\hline \multirow{2}{*}{ Cheap PT } & No & 355 & 637.5 & base & 669.7 & 265.1 & 450.9 & 754.6 \\
& Yes & 596 & 504.7 & $\mathbf{0 . 0 0 1}$ & 427.1 & 274.0 & 400.7 & 599.6 \\
\hline
\end{tabular}

Source: authors 


\subsection{Differences between Ostrava and Olomouc}

The previous section confirmed statistically significant differences in the walk distance to a public transport stop between the two cities, and the influence of several variables was confirmed. For a better understanding of the influence of individual variables, their impacts were evaluated for each city separately.

In the case of demographic characteristics (Table 6), previous findings (a significantly longer walk of younger respondents ages 15-24 (Ostrava) and 25-34 (Olomouc) than those ages 45-64) were confirmed for both cities. There was also a slight decrease with age increase. Men showed a significantly longer walking distance only in Ostrava, but gender seemed to have no impact in Olomouc.

Small average differences in walking distance are evident in Olomouc together with smaller variability than in Ostrava. It indicates that the situation in Olomouc is much more homogeneous. Due to small walking distance differences, the gender disparity in Olomouc is not significant. The same effect also influences low significances in Olomouc for other (following) parameters.

Also, the influence of economic activity on a shorter walking distance for pensioners and the unemployed was confirmed in Ostrava. Not surprisingly age-related factors are dominant for walking distances (age and retirement status) usually connected with growing health-related disabilities and limitations (Laverty et al. 2013; Adams et al. 2017).

Olomouc showed significantly shorter walks to stops in the case of the respondents with only primary education (as opposed to university-educated). However, this may have been influenced by the low number of respondents in this educational group. The influence of other variables on the declared walk distance has not been confirmed, and the results were consistent with findings from the analysis for both cities together.

In the case of transport behaviour, the impact of the preferred transport mode on walking distance was not confirmed, except for walk/bicycle

Table 6 Influence of demographic characteristics on walking distance in Ostrava and Olomouc (in meters)

\begin{tabular}{|c|c|c|c|c|c|c|c|c|c|}
\hline \multirow[b]{2}{*}{ Variable } & \multirow[b]{2}{*}{ Category } & \multicolumn{4}{|c|}{ Ostrava } & \multicolumn{4}{|c|}{ Olomouc } \\
\hline & & $\mathrm{N}$ & Mean & p-value & SD & $\mathrm{N}$ & Mean & p-value & SD \\
\hline \multirow{5}{*}{ Age } & $15-24$ & 78 & 968.5 & 0.000 & 1078.2 & 82 & 451.7 & 0.935 & 336.3 \\
\hline & $25-34$ & 92 & 699.7 & 0.888 & 500.1 & 84 & 480.4 & 0.007 & 444.1 \\
\hline & $35-44$ & 95 & 621.0 & 0.153 & 630.0 & 105 & 446.7 & 0.800 & 290.8 \\
\hline & $45-64$ & 114 & 611.7 & base & 552.2 & 137 & 421.2 & base & 294.5 \\
\hline & $65+$ & 81 & 491.1 & 0.070 & 306.1 & 86 & 436.3 & 0.150 & 365.7 \\
\hline \multirow{2}{*}{ Sex } & Male & 223 & 734.6 & base & 770.5 & 228 & 442.7 & base & 359.8 \\
\hline & Female & 237 & 610.1 & 0.005 & 537.6 & 266 & 445.8 & 0.678 & 326.7 \\
\hline \multirow{6}{*}{ Economic status } & Employee & 216 & 670.9 & 0.100 & 627.5 & 218 & 435.6 & 0.479 & 334.3 \\
\hline & Entrepreneur & 27 & 843.1 & base & 875.7 & 36 & 487.8 & base & 364.1 \\
\hline & Student & 74 & 857.0 & 0.971 & 933.7 & 89 & 441.2 & 0.429 & 336.5 \\
\hline & Unemployed & 29 & 576.0 & 0.000 & 357.7 & 19 & 449.2 & 0.424 & 253.9 \\
\hline & Paternal leave & 24 & 697.4 & 0.600 & 713.8 & 29 & 512.7 & 0.168 & 432.6 \\
\hline & Retired & 89 & 488.8 & 0.000 & 362.4 & 102 & 434.1 & 0.775 & 345.3 \\
\hline \multirow{4}{*}{ Education } & Primary school & 46 & 620.9 & 0.951 & 708.5 & 33 & 396.6 & 0.041 & 210.6 \\
\hline & Secondary school without GCSE & 135 & 584.4 & 0.453 & 548.0 & 101 & 432.3 & 0.994 & 384.6 \\
\hline & Secondary school with GCSE & 178 & 717.5 & 0.171 & 732.4 & 210 & 435.1 & 0.986 & 352.0 \\
\hline & University & 100 & 724.0 & base & 652.8 & 150 & 476.0 & base & 320.5 \\
\hline \multirow{5}{*}{ Persons in household } & 1 & 44 & 515.1 & 0.244 & 372.4 & 54 & 507.4 & 0.465 & 440.9 \\
\hline & 2 & 148 & 623.5 & base & 577.2 & 158 & 434.0 & base & 336.2 \\
\hline & 3 & 104 & 685.5 & 0.177 & 787.4 & 136 & 419.0 & 0.191 & 278.4 \\
\hline & 4 & 97 & 765.7 & 0.127 & 804.7 & 99 & 467.5 & 0.341 & 393.4 \\
\hline & $5+$ & 67 & 715.2 & 0.956 & 527.7 & 47 & 431.4 & 0.300 & 280.3 \\
\hline \multirow{2}{*}{ Child in household } & No & 314 & 657.0 & base & 639.4 & 362 & 438.4 & base & 342.2 \\
\hline & Yes & 146 & 699.5 & 0.387 & 712.5 & 132 & 460.7 & 0.532 & 342.3 \\
\hline \multirow{2}{*}{ Car in household } & No & 113 & 607.2 & base & 577.2 & 146 & 474.0 & base & 349.9 \\
\hline & Yes & 337 & 700.0 & 0.434 & 695.9 & 348 & 431.9 & 0.919 & 338.4 \\
\hline
\end{tabular}

Source: authors 
Table 7 Influence of transport characteristics on walking distance in Ostrava and Olomouc (in meters)

\begin{tabular}{|c|c|c|c|c|c|c|c|c|c|}
\hline \multirow[b]{2}{*}{ Variable } & \multirow[b]{2}{*}{ Category } & \multicolumn{4}{|c|}{ Ostrava } & \multicolumn{4}{|c|}{ Olomouc } \\
\hline & & $\mathrm{N}$ & Mean & $\mathrm{p}$-value & SD & $\mathrm{N}$ & Mean & $\mathrm{p}$-value & SD \\
\hline \multirow{4}{*}{ Preferred transport mode } & Car/motorbike & 117 & 704.6 & 0.748 & 633.5 & 104 & 466.4 & 0.476 & 321.2 \\
\hline & Walk/bicycle & 64 & 804.5 & 0.008 & 876.6 & 132 & 487.2 & 0.115 & 377.0 \\
\hline & Public transport & 249 & 633.7 & base & 637.6 & 240 & 418.9 & base & 314.8 \\
\hline & Other & 30 & 556.9 & 0.377 & 370.8 & 18 & 342.4 & 0.503 & 491.5 \\
\hline \multirow{2}{*}{ Attractive PT } & No & 246 & 729.4 & base & 772.2 & 156 & 488.5 & base & 425.5 \\
\hline & Yes & 210 & 610.5 & 0.015 & 503.8 & 338 & 424.0 & 0.010 & 294.2 \\
\hline \multirow{2}{*}{ Reliable PT } & No & 70 & 925.4 & base & 1020.4 & 63 & 479.7 & base & 472.3 \\
\hline & Yes & 388 & 627.4 & 0.000 & 566.1 & 431 & 439.2 & 0.239 & 319.0 \\
\hline \multirow{2}{*}{ Clean PT } & No & 217 & 670.4 & base & 658.2 & 136 & 489.9 & base & 387.9 \\
\hline & Yes & 239 & 675.8 & 0.500 & 672.1 & 358 & 427.1 & 0.106 & 321.8 \\
\hline \multirow{2}{*}{ Safe PT } & No & 124 & 592.6 & base & 558.1 & 87 & 460.9 & base & 405.5 \\
\hline & Yes & 334 & 702.8 & 0.128 & 696.9 & 407 & 440.8 & 0.403 & 327.4 \\
\hline \multirow{2}{*}{ Comfortable PT } & No & 222 & 748.8 & base & 804.1 & 151 & 460.7 & base & 366.7 \\
\hline & Yes & 235 & 602.1 & 0.007 & 488.0 & 343 & 437.2 & 0.809 & 330.9 \\
\hline \multirow{2}{*}{ Fast PT } & No & 171 & 759.0 & base & 787.7 & 136 & 484.1 & base & 422.8 \\
\hline & Yes & 287 & 621.6 & 0.012 & 572.2 & 358 & 429.3 & 0.088 & 305.2 \\
\hline \multirow{2}{*}{ Cheap PT } & No & 258 & 696.6 & base & 739.2 & 97 & 480.4 & base & 395.5 \\
\hline & Yes & 199 & 642.8 & 0.027 & 552.1 & 397 & 435.6 & 0.028 & 327.6 \\
\hline
\end{tabular}

Source: authors

in Ostrava, where declared walk was significantly longer than when using public transport (see Table 7). Important factors that were associated with a shorter walking distance to the stop included positive respondent opinions on urban public transport. This was confirmed in Ostrava, where the significant factors included attractiveness, reliability, comfort, speed, and price. People positively assessing public transport in these aspects walked a shorter distance to a stop. The situation was different in Olomouc, and even though the walking distances were shorter for the respondents who provided positive assessment, attractiveness and price were the only variables with a significant impact. These results are related to a different opinion on urban public transport quality in both cities and differences in walking distances in both cities. The last factor, which was evaluated only at the level of individual cities, is the type of housing. Both cities were divided into three areas according to the predominant housing type - areas with urban housing (including housing estates), family houses, and surrounding areas outside the administrative borders of the city, which is typical of a more rural environment (see Table 8). It is evident that the type of housing had a significant impact on the resulting walking distance to a stop. In Ostrava, people living in an area of urban housing walk the shortest distance. In the case of respondents from family houses, the difference was quite significant-the walking distance was two-thirds longer on aver-

Table 8 Influence of urban characteristics on walking distance in cities (m)

\begin{tabular}{|c|c|c|c|c|c|c|c|c|}
\hline Variable & Category & $\mathrm{N}$ & Mean & $\mathrm{p}$-value & SD & LQ & Median & UQ \\
\hline \multicolumn{9}{|c|}{$\begin{array}{ll} & \text { Ostrava }\end{array}$} \\
\hline \multirow{3}{*}{ Urban characteristic } & Urban housing incl. housing estates & 267 & 542.6 & base & 428.5 & 275.6 & 444.2 & 678.4 \\
\hline & Family houses & 71 & 756.3 & 0.000 & 660.6 & 300.4 & 575.0 & $1,020.5$ \\
\hline & Suburbs & 122 & 900.5 & 0.000 & 957.9 & 369.2 & 653.5 & 840.2 \\
\hline \multicolumn{9}{|c|}{ Olomouc } \\
\hline \multirow{3}{*}{ Urban characteristic } & Urban housing incl. housing estates & 337 & 447.0 & base & 297.3 & 254.7 & 374.1 & 548.5 \\
\hline & Family houses & 91 & 372.8 & 0.599 & 307.1 & 188.9 & 293.5 & 501.5 \\
\hline & Suburbs & 66 & 529.5 & 0.001 & 534.0 & 197.0 & 425.7 & 548.1 \\
\hline
\end{tabular}

Source: authors 


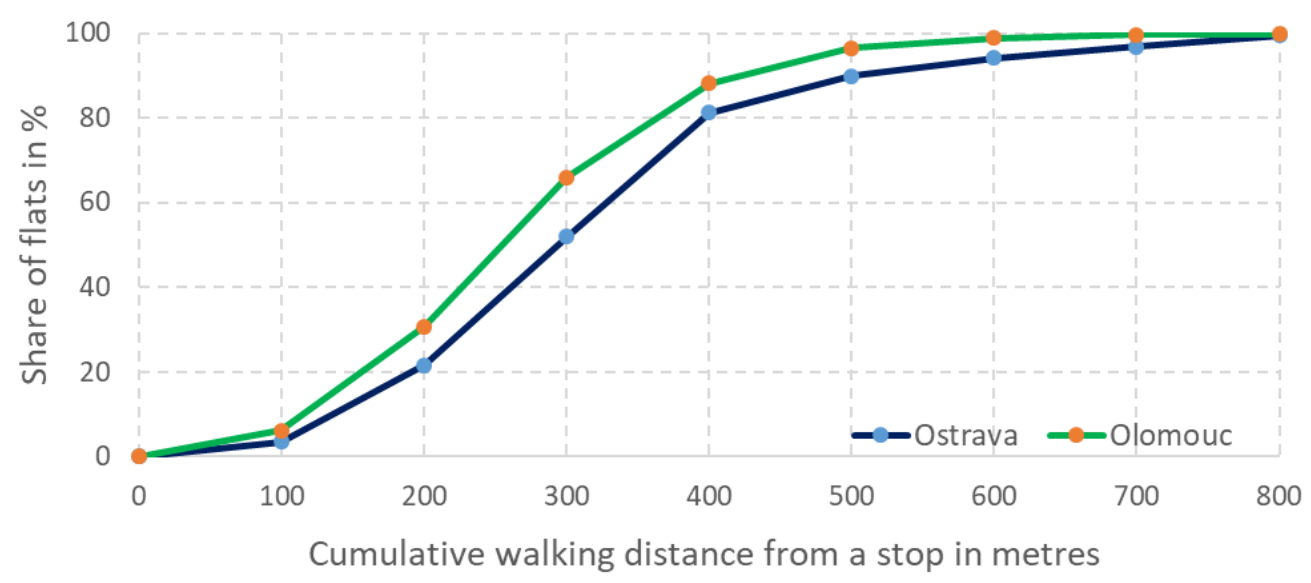

Fig. 2 The cumulative share of flats according to walking distance from a public transport stop, authors.

age. The disparity increased mainly in the second half of the records (the difference of upper quartiles). The opposite situation was in Olomouc, where the shortest walking distance was in the case of family houses. However, this was not significantly lower than in the case of respondents from urban housing types. What, again, corresponds to the assumption that Olomouc is a more compact city where, regarding urban transport, there is no noticeable difference in walking distance to a public transport stop between both urban housing and family houses. The situation was different in the suburbs, where, in both cases, the walking distance had significantly increased, as was expected. However, there are differences - in Olomouc such extension (suburb - base) represents only $18 \%$ while in Ostrava it is $66 \%$. If both cities are compared in the same category, $21 \%$ increase for urban housing is found in Ostrava (compare to Olomouc), 70\% for suburbs and $103 \%$ for family housing.

\section{Service area of public transport stops}

The average walking distance to a stop is approximately $30 \%$ less in Olomouc than in Ostrava, which is explained by the different urban structures and different levels of urbanisation of both cities. To understand the reasons for this difference and to determine the impact of differences in the efficiency of transport networks in both cities, the average service area of all public transport stops was delimited. For each stop, eight service areas delimited by 100 -meter long walking distance were generated followed by determination of the percentage share of flats in residential buildings (data from the Register of Enumeration Districts and Buildings,
Czech Statistical Office). Fig. 2 shows that in Olomouc, there are more flats near each stop, with $66 \%$ of all flats within walking distance of 300 meters, but in Ostrava, it was only $52 \%$. However, with increasing distance, the differences tend to even out, and for up to 600 meters the difference is only less than $5 \%$ for flats, and within 800 meters there are more than $99 \%$ of all flats in residential buildings of both cities. While the situation in Olomouc seems to be close to other middle-size historical cities in the Czechia (i.e. Kraft 2016, found in České Budějovice that half of the city population live within a distance of up to 280 metres from the nearest public transport stop), Ostrava is different.

Based on these data, an average walking distance to the nearest stop in Olomouc is 312 meters, and in Ostrava, it is 357 metres ( $+14 \%$ longer). This increase, therefore, explains only half of the $30 \%$ difference in walking distance; the second half consists of a walk to a farther stop from a respondent's residence. In the questionnaire, passengers reported their place of residence and the name of the stop they use most frequently. It is, thus, possible to also consider whether the stop that they declared they use for their commuting was the closest one to their home. In the case of assessment of the service area of individual stops, the stop closest to a place of residence is usually evaluated without assessing whether a given stop provides the appropriate transport connections. Thus, a walking distance to the 50 nearest public transport stops from each known respondent's residence was determined. The same source data were used as in the case of determination of walking distances in the previous sections. Subsequently, distance to a declared stop was compared with the distances to nearby stops and determined its order.

According to the results (Table 9), the public transport stop reported as being closest to a respon- 
dent's residence was used by only $51 \%$ of all respondents. Another $20 \%$ of residents used the second closest stop, $11 \%$ the third, and subsequent stops (up to the seventh stop) were used by approximately $2-4 \%$. When comparing both cities, the two closest stops were used more frequently in the case of Olomouc, and the more distant stops were used in Ostrava (except for the fifth stop in order), which confirms the assumptions stated above. This difference indicates potential issues in the organisation of urban public transport related to the direction of links, continuity of connections, scheduling problems and others. The results of the use of stops according to order also corresponded to the conclusions by Ivan (2010), although this paper did not work with urban public transport.

Table 9 Percentage use of public transport stops near Respondents in Olomouc and Ostrava

\begin{tabular}{lrrr}
\hline $\begin{array}{l}\text { Stop Order } \\
\text { to residence }\end{array}$ & Total & Olomouc & Ostrava \\
\hline 1st & 51.0 & 56.5 & 45.7 \\
2nd & 19.7 & 20.2 & 19.3 \\
3rd & 10.9 & 8.7 & 13.1 \\
4th & 3.6 & 2.3 & 4.9 \\
5th & 3.8 & 4.2 & 3.3 \\
6th and farther & 11.0 & 8.1 & 13.7 \\
\hline Source: authors & & &
\end{tabular}

By comparing actual walking distances to declared stops according to their order from the place of residence, it is possible to determine that walking distances to all the stops in Ostrava are longer, as illustrated in Fig. 3. In the case of the first three closest stops, the walking distance in Ostrava was always longer by one-third and was also similar in the case of more distant stops (except the fourth stop in the order). The average values in the case of walking distance to the sixth and other more distant stops comprised only a few records, meaning that these results are highly unstable.

To conclude what is causing the preference for more remote stop it would be necessary to ask the respondents directly. In case the respondents commented purposes, they select the stop based on these factors:

- number of transport connections servicing the stop and time of departures,

- seamless connection to the destination,

- the speed of preferred transport connection (e.g. trams are faster than buses and trolleybuses, public transport vs walking),
- potential delays (e.g. trams tend to have fewer delays than buses at peak hours),

- equipment of stops and nearby areas (e.g. ticket machine, shelter, bench, grocery, newspaper store),

- the comfort of vehicle/link servicing more remote stop (e.g. low-floor, empty seats, possibly dangerous or annoying fellow travellers),

- preference of a previous stop along the route to avoid overcrowded stop with passengers waiting for the same connection during peak hours,

- other personal factors, e.g. to avoid dangerous/dodgy areas.

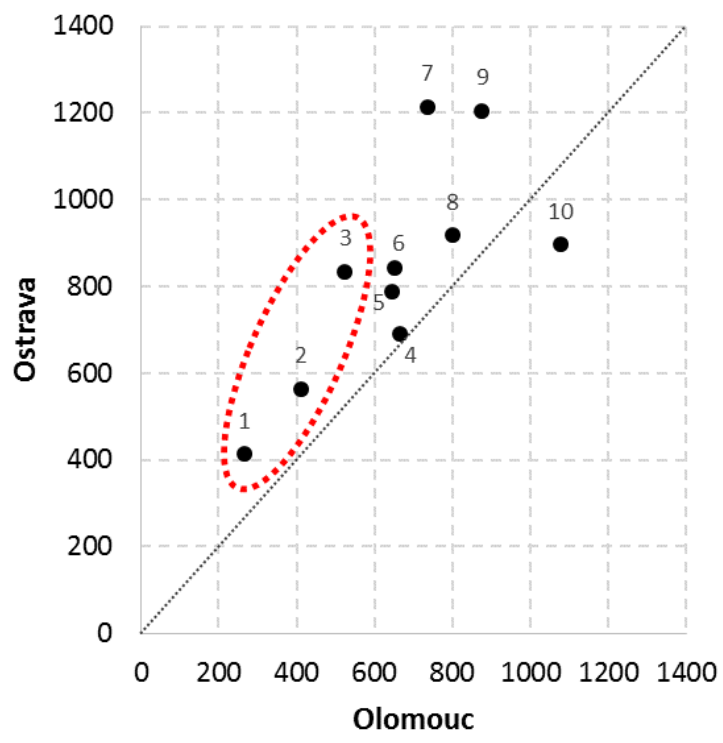

Fig. 3 Comparison of average walking distance (in meters) to a used stop by order, authors.

\section{Conclusions}

This paper evaluated walking distances to the preferred public transport stop in two selected regional cities in the Czech Republic, Ostrava and Olomouc. Analysis of the results of the survey conducted in collaboration with local transit agency and City Council, which included nearly 1,000 respondents, showed the existence of significant effects of selected factors affecting a walking distance to a preferred stop. Walking time reported directly by respondents proved to be less reliable, mainly because the respondents intended to mention multiples of five minutes. Therefore, it was more suitable 
to use a walking distance calculated using network analysis.

The most significant influence is caused by the urbanisation of the city and the transport infrastructure. The polycentric character of Ostrava city with less dense building pattern and wide streets from industrialisation era development significantly determines distances in the city and also a parameter such as walking distance. On the contrary, Olomouc as an example of a compact historical city has denser urbanisation (Burian, Brus, Voženílek, 2013) inducing shorter walking distances to a preferred public transport stop. The issue moreover strengthens the influence of different types of urbanisation that more areas were classified as a suburb in Ostrava (27\%) than in Olomouc with only $13 \%$.

Urban characteristics also showed a significant effect on walking distance. In Ostrava, shorter distances were in typical urban housing areas, and significantly longer distances were in areas with prevailing family houses or in the suburbs. In Olomouc, the situation inside the city was very similar, and there were no significant differences. Walking distance was significantly longer only in areas around the city (suburbs). There are apparent differences between both cities - all distances are longer in Olomouc while the increase in an urban category is only about $21 \%$ but in suburb category about $70 \%$ and in family housing category about even $103 \%$. The longer distances in the suburbs in Ostrava are not caused only by existing differences between both cities. If only the situation inside the city is studied, the extension of walking distances in the suburbs compared to urban housing (as a base) in Olomouc is only 18\% while in Ostrava it is $66 \%$.

Also, the structure and organisation of urban public transport and various transport characteristics significantly contribute to the influence of urban factor. Travellers in Ostrava prefer more often more distant urban public transport stop for travelling. The closest stops are used about 10\% less in Ostrava than in Olomouc, and the more distant stops are used for travelling more significantly; almost $14 \%$ in case of the sixth and more distant stop. Travellers explain this fact by various reasons such as low frequency of connections, indirect connections, slower speed, bad equipment, crowded and fear or discomfort. Some of these aspects are directly pointing out a worse organisation of urban public transport that force people to walk to a more remote public transport stop.

Both factors cause that the average walking distance is 568 metres in Ostrava while only 439 metres in Olomouc. Both values are within the range published abroad; nevertheless, the size of the difference is significant. Based on the analysis of flat distribution in Ostrava, it can be stated that increasing distance from public transport stops is caused from one third by differences in urbanisation and the other two-thirds are caused by differences in the organisation of public transport and other related factors. Furthermore, the differences in respondents' structure are marginal. A significant majority of longer distances in Ostrava is evident in all individual age and economic categories (including pensioners). Additionally, much higher variability of walking distances is proven for the majority of categories in Ostrava what denotes much more heterogeneous urban areas and related conditions for walking to public transport stops. The differences are partly proved by reported walking times of respondents where public transport stop within 5 minutes is reported by $83 \%$ of respondents in Olomouc while only $55 \%$ in Ostrava. Smaller walking distances in Olomouc lead to minimal differences among categories that are not statistically significant. In Ostrava, on the other hand, the differences are often statistically significant thank to longer distances (even with higher variability).

The analysis of demographic factors confirmed the expected trend of decreasing walking distance with increasing age. It was proved namely for the youngest group (15-24) in Ostrava (extremely high mean and SD). Significantly shorter distances refer to the female population in Ostrava, retired (connected with high age) and unemployed. While male longer strides can explain gender differences, and the situation for unemployed may be explained by the low influence of (relatively high) transport accessibility for employment inside a city. Assumption of the negative influence of the higher number of family members, higher salaries and worse education (blue collar) was not proved; on the contrary, significantly shorter walking distances are evident by the unemployed. The reason for this specific situation can be related to the urban environment where standard assumptions do not have to be proved or are very weak.

The other surprising result is no influence on transport mode and car ownership on walking distances. It was assumed that a predominantly-used transport mode would affect walking distance; however, this was not confirmed, and walking distance was independent of the most frequently used type of transport mode. This fact can be explained by weakened advantage of car ownership in a city compared to a rural environment.

Investigation of respondents' opinion about the quality of public transport provides positive 
evaluation for shorter distances for almost all investigated parameters except for cleanness and safety. It seems the closeness of preferred public transport stop influences the resulting opinion -namely its attractiveness, reliability, comfort, and speed. It is probably connected with the usage of closer or distant public transport stops. Using more distant stops prove dissatisfaction with the situation at closer stops and logically a traveller who has to walk to a more remote stop will evaluate attractivity, comport and other related parameters worse. The preference of closer stop can support the general use of public transport. Also, the evaluation of speed and comfort can be influenced by the fact that shorter walking distances eliminate long and slow walk and significant discomfort.

These findings are useful for transport and urban planners for several reasons. Firstly, accepted walking distance to the preferred transport stop is defined and additionally, service areas of individual stops can be delimited aiming to locate inaccessible areas in the cities. Secondly, various factors were proved to influence the final walking distance. These accepted distances can be compared with the local walking distances and structure of population to find problematic areas with above-average walking distances related to a dominant population group. This result can contribute to the optimisation of public transport stop distribution.

Information about the low use of the closest stops is essential for public transport providers. It provides a possibility to improve the level of transport services of those public transport stops that are close to potential passengers but do not provide efficient connections (mainly in case of the Ostrava Transport Agency). These stops could be either cancelled or upgraded to offer faster/more frequent transport connections.

From the methodological point of view, the significant use of more remote public transport stops supports previous results published by Ivan (2010). Accessibility analyses working with the closest stop only are unreal and bias results under the conditions in the Czechia. In Ostrava, the closest stop is preferred by less than half of respondents (in Olomouc by 57\%), and even more remote stops have a significant share of use for travelling. It was noted that data from questionnaires were influenced by several factors, mainly their completeness, accuracy, and veracity. Opportunities for further research include, in particular, obtaining and analysing data from other sources independent of any personal reports of respondents and their interpretations. An overview of possibilities to use modern IT technologies for gathering information in the field of transportation is provided by, for example, van Wee et al. (2013). In this case, it would have been beneficial to use GPS trackers, mobile phones, or other geolocation services (e.g. Google Timeline), making it possible to analyse more accurately and quickly the mobility of the population during the day.

\section{Acknowledgement}

The authors gratefully acknowledge the support of the Czech Science Foundation (project no. 14-26831S - Spatial simulation modelling of accessibility).

\section{References}

Adams EJ, Esliger DW, Taylor IM, Sherar LB (2017) Individual, employment and psychosocial factors influencing walking to work: Implications for intervention design. PLoS ONE 12(2).

Ayvalik CK, Khisty CJ (2002) Heuristic analysis of impacts of commuter rail station consolidation on pedestrian access. Transportation Research Record 1793: 47-54.

Bernard HR (2012) Social Research Methods: Qualitative and Quantitative Approaches. SAGE Publications, London.

Biba S, Curtin SK, Manca G (2010) A new method for determining the population with walking access to transit. International Journal of Geographical Information Science 24(3): 347-364.

Bilková K, Križan F, Horňák M, Barlík P, Kita P (2017) Comparing two distance measures in the spatial mapping of food deserts: The case of Petržalka, Slovakia. Moravian Geographical Reports 25(2): 95-103

Burian J, Brus J, Voženílek V (2013) Development of Olomouc City in 1930- 2009: based on analysis of functional areas. Journal of Maps 9(1): 64-67.

Burian J, Brychtová A, Vávra A (2015) Analytical material for planning in Olomouc, Czech Republic. Journal of Maps 12(4): 649-654.

Burian J, Zajíčková L, Ivan I, Macků K (2018) Attitudes and motivation to use public or individual transport: a case study of two middle-sized cities. Social Sciences 7(6): 1-25.

Currie G (2010) Quantifying spatial gaps in public transport supply based on social needs. Journal of Transport Geography 18(1): 31-41.

Čekal J (2006) Jihočeský kraj: regionálně geografická analýza prostorové mobility obyvatelstva. Brno: Regionální geografie a regionální rozvoj, Masarykova univerzita. Ph.D. Theses.

Daniels R, Mulley C (2013) Explaining walking distance to public transport: the dominance of public transport supply. The Journal of Transport and Land Use 6(2): 5-20.

Dill J (2003) Transit use and proximity to rail: results from large employment sites in the San Francisco, California, Bay area. Transportation Research Record 1835: 19-24.

Durček P, Horňák M (2016) Population potential within the urban environment and intra-urban railway network opportunities in Bratislava (Slovakia). Moravian Geographical Reports 24(4): 52-64. 


\section{sciendo}

El-Geneidy A, Grimsrud M, Wasfi R, Tétreault P, SurprenantLegault J (2014) New evidence on walking distances to transit stops: identifying redundancies and gaps using variable service areas. Transportation 41(1): 193-210.

El-Geneidy AM, Tétreault PR, Surprenant-Legault J (2009) Pedestrian access to transit: identifying redundancies and gaps using a variable service area analysis. Transportation Research Board 89th Annual Meeting.

Fotheringham AS, Wong DW (1991) The modifiable areal unit problem in multivariate statistical analysis. Environment and Planning A 23(7): 1025-1044.

Fransen K, Neutens T, Farber S, De Maeyer P, Deruyter G, Witlox F (2015) Identifying public transport gaps using timedependent accessibility levels. Journal of Transport Geography 48: 176-187.

Furth PG, Mekuria MC, Sanclemente JL (2007) Stop spacing analysis using geographic information system tools with parcel and street network data. Transportation Research Record 2034: 73-81.

García-Palomares JC, Gutiérrez J (2013) Walking accessibility to public transport: an analysis based on microdata and GIS Environment and Planning B: Planning and Design 40(6): 1087-1102.

Gutiérrez J, García-Palomares JC (2008) Distance-measure impacts on the calculation of transport service areas using GIS. Environment and Planning B: Planning and Design 35(3): 480-503.

Hernández D, Witter R (2015) Perceived vs. actual distance to transit in Santiago, Chile. Journal of Public Transportation 18(4): 16-30.

Hruška-Tvrdý L, Kukuliac P, Horák J, Ivan I, Foldynová I (2012) Socioeconomic atlas of Ostrava. In: Klímová V, Zítek V (eds) 15th International Colloquium on Regional Sciences. Masaryk University, pp. 181-192.

Hsiao S, Lu J, Sterling J, Weatherford M (1997) Use of geographic information system for analysis of transit pedestrian access. Transportation Research Record 1604: 50-59.

Hyvnar V, Rohrerová L et al. (2016): Limits of land use. Institute for Spatial Development. <http://www.uur.cz/default.asp?ID=2591>

Ivan I (2010) Docházka na zastávku a její vliv na dojíždku do zaměstnání. Geografie 115(4): 393-412.

Kimpel, T., Dueker, K., El-Geneidy, A. (2007): Using GIS to measure the effect of overlapping service areas on passenger boardings at bus stops. URISA Journal 19: 5-11.

Kozel P, Orlíková L, Michalcová S (2018) The modified rural postman problem in vehicle route optimization. Communications Scientific Letters of the University of Zilina 20(3): 88-92.

Kraft S (2011) Aktuální změny v dopravním systému České republiky: geografická analýza. Brno, Ph.D. Theses.

Kraft S (2016) Measuring and modelling the spatial accessibility of public transport stops in GIS. Hungarian Geographical Bulletin 65(1): 57-69.

Langford M, Fry R, Higgs G (2012) Measuring transit system accessibility using a modified two-step floating catchment technique. International Journal of Geographical Information Science 26(2): 193-214.
Laverty AA, Mindell JS, Webb EA, Millett C (2013) Active travel to work and cardiovascular risk factors in the United Kingdom. American Journal of Preventive Medicine 45(3): 282-288.

Loutzenheiser D (1997) Pedestrian access to transit: Modeling of walk trips and their design and urban form determination around bay area rapid transit stations. Transportation Research Record 1604: 40-49.

L'uptak V, Gasparik J, Chovancová M (2017) Proposal for evaluating a connection quality within transport networks. In: Proceedings of the 18th International Scientific Conference on LOGI Location: Ceske Budejovice. MATEC Web of Conferences, Vol. 134, Article 00033. MATEC Web of Conferences 134, 00033.

Mavoa S, Witten K, McCreanor T, O'Sullivan D (2012) GIS based destination accessibility via public transit and walking in Auckland, New Zealand. Journal of Transport Geography 20: 15-22.

MD (2014) Transport Yearbook - Czech Republic, 2014. Ministry of Transport.

Olivková I (2015) Model for measuring passenger satisfaction and assessing mass transit quality. Journal of Public Transportation 18(3): 52-70

O'Neill WA, Ramsey RD, Chou J (1992) Analysis of transit service areas using geographic information systems. Transportation Research Record 1364: 131-138.

Peng A, Dueker K, Strathman J, Hopper J (1997) A simultaneous route level transit patronage model: demand, supply and inter-route relationship. Transportation Research Record 24: 159-181.

Pucher J (1999) The transformation of urban transport in the Czech Republic, 1988-1998. Transport Policy 6(4): 225-236.

Seidenglanz D (2007) Dopravní charakteristiky venkovského prostoru. Brno, Katedra Regionální geografie a regionálního rozvoje PřF Masarykovy univerzity. Ph.D. Theses.

Van Wee B, Geurs K, Chorus C (2013) Information, communication, travel behavior and accessibility. The Journal of Transport and Land Use 6(3): 1-16.

Van Wee B (2016) Accessible accessibility research challenges. Journal of Transport Geography 51: 9-16.

Whyte WH (2012) City: rediscovering the center. University of Pennsylvania Press.

Witlox F (2015) Beyond the data smog? Transportation Revue 35(3): 245-249.

Wu BM, Hine JP (2003) A PTAL approach to measuring changes in bus service accessibility. Transport Policy 10(4): 307-320.

Yigitcanlar T, Sipe NG, Evans R, Pitot M (2007) A GIS-based land use and public transport accessibility indexing model. Australian Planner 44(3): 30-37.

Zajíčková L (2012) Časové variace dojíždky do města Olomouc prostředky hromadné dopravy osob. Olomouc. Univerzita Palackého v Olomouci. Diploma Thesis.

Zhao F, Chow L-F, Li M-T, Gan A, Ubaka I (2003) Forecasting transit walk accessibility - regression model alternative to buffer method. Transportation Research Record 1835: 34-41. 